Research Article

\title{
A Modified Newmark Methodology for Permanent Deformation Analysis of Rock-Fill Dams
}

\author{
Hongjun Li $(\mathbb{D}$, Hong Zhong, Zuwen Yan, and Jianming Zhao \\ State Key Laboratory of Simulation and Regulation of Water Cycle in River Basin, \\ China Institute of Water Resources and Hydropower Research, Beijing 100048, China \\ Correspondence should be addressed to Hongjun Li; lihj@iwhr.com
}

Received 8 December 2017; Accepted 13 February 2018; Published 1 April 2018

Academic Editor: Haiyun Shi

Copyright (C) 2018 Hongjun Li et al. This is an open access article distributed under the Creative Commons Attribution License, which permits unrestricted use, distribution, and reproduction in any medium, provided the original work is properly cited.

Newmark sliding block approach has been extensively studied by many researchers in the past decades. Significant progress has been made to alleviate its deficiencies and overcome its simplifying assumptions, but some aspects such as the cyclic shear strength and time history vertical acceleration in the Newmark sliding displacement analysis are seldom considered strictly. In the presented research, a modified Newmark methodology for sliding deformation analysis of rock-fill dams subjected to strong earthquake is proposed. In order to make the seismic safety evaluation of dams more realistic, the influence of cyclic shear strength (earthquake-induced reduction of shear strength) and time history vertical acceleration obtained from the dynamic response analysis on the critical acceleration and accumulative sliding displacement of the flexible sliding body is considered. Detailed comparison between the proposed method and existing methods is performed via the analysis of two typical dams, that is, a virtual rock-fill dam with a height of $100 \mathrm{~m}$ which is assumed to be situated on rock formation and a real core rock-fill dam with a height of $150 \mathrm{~m}$ built on deep overburden layers. It is demonstrated that the cyclic shear strength and time history vertical acceleration within flexible sliding body, as highlighted in the proposed method, have significant effect on the seismic safety evaluation, critical acceleration, and accumulation of sliding deformation of rock-fill dams subjected to strong earthquake loading. The existing approaches tend to provide unconservative evaluation on the consequences of earthquakes on rock-fill dams.

\section{Introduction}

Nowadays, the evaluation on the seismic performance of rock-fill dams and Earth slopes subjected to strong earthquakes is performed utilizing not only the traditional forceoriented factor of safety, but also the magnitude of the accumulative earthquake-induced sliding displacement [1-3]. A strict and simple prediction of earthquake-induced sliding displacement can directly show the potential consequences of earthquakes on rock-fill dams. In 1965, an original procedure for the prediction of earthquake-induced sliding displacement was formulated by Newmark [4]. Through this research, it is revealed that irregular inertial force induced by earthquake acceleration could exert a driving force sufficient to reduce temporarily the factor of safety below one and then result in several sliding episodes during the shaking. As pointed out by Newmark, sliding episodes in earthquakes occur when the critical acceleration is exceeded and continues until the velocity of downward movement reduces to zero. So the accumulation of permanent sliding displacement (Newmark sliding displacement), with its magnitude equal to the summation of all downward movements during the shaking, could be a useful index to evaluate the stability of slopes during earthquakes.

In the early Newmark-type method, the flexible sliding body is modeled as a rigid block, and only two parameters are used, that is, the input ground motion and the critical acceleration $\left(k_{y} \mathrm{~g}\right.$, the horizontal acceleration that results in unit pseudostatic factor of safety). Due to its effectiveness and simplicity, the Newmark sliding rigid block approach has been extensively adopted and studied by many engineers and researchers in the past decades. Much great progress has been made to alleviate its limitations and overcome its simplifying assumptions; for example, the flexibility of the sliding mass is 
firstly considered instead of the assumption of rigid body by Makdisi and Seed [5]. However, the research on the influence of the cyclic shear strength (or dynamic pore pressure) and time history vertical acceleration on the critical acceleration and accumulation of sliding displacement is still limited. Meanwhile, the application of this approach for the seismic stability evaluation of high rock-fill dams with a height over $250 \mathrm{~m}$ or around $300 \mathrm{~m}$ is also limited. Thus, with the development of testing apparatus and technology for cyclic shear strength of rock-fill materials under cyclic loading, it is suggested that the seismic design and assessment of the effectiveness of mitigation measures for rock-fill dams subjected to earthquake be performed strictly based on the cyclic shear strength [6-9].

On the other hand, a theoretically reasonable and practically feasible method for prediction of earthquake-triggered sliding displacement is required necessarily for the seismic design and stability analysis for emerging high rock-fill dams. Therefore, special emphasis of this paper will be placed on the determination of critical acceleration of flexible sliding body based on the cyclic shear strength and time history vertical acceleration aiming at more realistic evaluation of earthquakeinduced sliding displacement of high rock-fill dams.

\section{Cyclic Shear Strength of Rock-Fill Materials}

The first aim of this study is to analyze the effect of cyclic shear strength on earthquake-induced sliding displacements using the modified Newmark method in order to improve the ability of predicting seismic stability of rock-fill dams. It must be noted that the liquefaction-induced instability has not been included in this paper. As we know, in the earthquake, instability occurs when the dynamic shear stresses required to maintain equilibrium of a soil deposit exceed the static shear strength of that deposit. Then it will recombine the structure character of soil's particle until the new equilibrium can reach. The shear strength of soil in this new equilibrium will be regarded as cyclic shear strength.

The cyclic shear strength is an important parameter in seismic design and stability analyses of rock-fill dams. For some typical rock-fill materials, such as fine sand, clay, and sand gravel, the significant cyclic loading induced by irregular strong earthquake usually leads to the obvious degeneration of the undrained shear strength [10, 11]. Some accidents of rock-fill dams occurred due to the decrease of cyclic shear strength. The postcyclic undrained shear behavior of rock-fill materials under cyclic loading has been the focus in the past decades. Nowadays, some considerable advances of testing apparatus and technology for cyclic shear strength of rock-fill materials have been obtained; for example, the cyclic triaxial undrained compress tests and simple shear tests have been used extensively to study the cyclic shear strength of rock-fill materials. From the tests, it is shown that the cyclic undrained shear strength is often related to the confining pressure $\left(\sigma_{0}^{\prime}\right)$, failure number of cycles $\left(N_{f}\right)$, and the failure strain criterion (5\% or $\left.10 \%\right)$. In general, the correlation of undrained cyclic shear strength $\left(\tau_{f s}\right)$, confining pressure, and cyclic shear stress $\left(\tau_{d}\right)$ acting on the failure surface can be formulated by (1-5). In addition, it is noted that the lower value between the static shear strength and cyclic shear strength should be adopted in the seismic design and stability analysis of rock-fill dams.

$$
\begin{aligned}
\sigma_{f 0}^{\prime} & =\sigma_{0}^{\prime}+\tau_{0} \sin \phi^{\prime}\left(\frac{\tau_{d}>\tau_{0}}{\sin \phi^{\prime}}\right), \\
\sigma_{f 0}^{\prime} & =\sigma_{0}^{\prime}-\tau_{0} \sin \phi^{\prime}\left(\frac{\tau_{d} \leq \tau_{0}}{\sin \phi^{\prime}}\right), \\
\tau_{f 0} & =\tau_{0} \cos \phi^{\prime} \\
\alpha & =\frac{\tau_{f 0}}{\sigma_{f 0}^{\prime}}, \\
\left(\Delta \tau_{f}\right)_{n} & =c_{r}\left(\frac{\tau_{d}}{\sigma_{0}^{\prime}}\right)_{n} \sigma_{0}^{\prime} \quad(\alpha<0.15), \\
\left(\Delta \tau_{f}\right)_{n} & =\left(\frac{\tau_{d}}{\sigma_{0}^{\prime}}\right)_{n} \sigma_{0}^{\prime} \cos \phi^{\prime} \quad(\alpha \geq 0.15), \\
\tau_{f s} & =\left(\Delta \tau_{f}\right)_{n}+\tau_{f 0}\left(\frac{\tau_{d} \leq \tau_{0}}{\sin \phi^{\prime}}\right), \\
\tau_{f s} & =\left(\Delta \tau_{f}\right)_{n}-\tau_{f 0}\left(\frac{\tau_{d}>\tau_{0}}{\sin \phi^{\prime}}\right)
\end{aligned}
$$

Here, $\sigma_{1}^{\prime}$ and $\sigma_{3}^{\prime}$ are the major principle effective stress and minor principle effective stress, respectively; $\tau_{d}$ is the cyclic shear stress; $\sigma_{0}^{\prime}$ is the initial effective confining pressure with $\sigma_{0}^{\prime}=\left(\sigma_{1}^{\prime}+\sigma_{3}^{\prime}\right) / 2 ; \tau_{0}$ is the initial static shear stress with $\tau_{0}=\left(\sigma_{1}^{\prime}-\sigma_{3}^{\prime}\right) / 2 ; c_{r}$ is the correction coefficient of cyclic shear strength; $\tau_{f 0}$ and $\sigma_{f 0}^{\prime}$ are the initial shear stress and normal stress acting on the failure surface, respectively; $\left(\Delta \tau_{f}\right)_{n}$ is the variation of cyclic shear strength at a given number of cycles; $n$ is the number of cycles; $\phi^{\prime}$ is the effective friction angle; and $\alpha$ is the initial shear stress ratio on the failure surface.

For the sake of simplicity and convenience in application, based on the available data of rock-fill materials obtained by the dynamic triaxial compress tests and by referring to the mode of Mohr-Coulomb principle, the cyclic shear strength can be represented by a simple equation, as (6). Then, the cyclic shear strength of rock-fill materials can be easily determined from the number of cycles, confining pressure, and shear stress ratio on the failure surface.

$$
\begin{aligned}
\tau_{f s} & =\left(\tau_{f s 0}\right)_{\alpha}+\tan \phi_{d \alpha} \sigma_{f 0}^{\prime}, \\
\left(\tau_{f s 0}\right)_{\alpha} & =\tau_{f s 0}+\zeta \alpha, \\
\tan \phi_{d \alpha} & =\tan \phi_{d 0}+\beta \alpha .
\end{aligned}
$$

Here, $\left(\tau_{f_{s 0}}\right)_{\alpha}$ and $\tan \phi_{d \alpha}$ are the equivalent cyclic cohesion and friction coefficient, respectively, which can be directly introduced into the modified Newmark sliding displacement analysis. Both of them are in proportion to the initial shear stress ratio on the failure surface, as in (7) and (8). $\tau_{f s 0}$ and $\tan \phi_{d 0}$ are the cyclic shear strength parameters as $\alpha$ equals zero, and $\varsigma$ and $\beta$ are proportional coefficients. 
TABLE 1: Parameters of total shear strength.

\begin{tabular}{|c|c|c|c|c|c|c|c|c|c|c|c|}
\hline \multirow[b]{2}{*}{ Soil } & \multirow{2}{*}{$r\left(\mathrm{~g} / \mathrm{cm}^{3}\right)$} & \multirow[b]{2}{*}{$k_{c}$} & \multirow[b]{2}{*}{$\sigma_{3}^{\prime}(\mathrm{kPa})$} & \multirow[b]{2}{*}{$\sigma_{0}^{\prime}(\mathrm{kPa})$} & \multirow[b]{2}{*}{$\tau_{0}(\mathrm{kPa})$} & \multirow[b]{2}{*}{$\tau_{f 0}(\mathrm{kPa})$} & \multirow[b]{2}{*}{$\sigma_{f 0}^{\prime}(\mathrm{kPa})$} & \multirow[b]{2}{*}{$\tau_{f 0} / \sigma_{f 0}^{\prime}$} & \multicolumn{3}{|c|}{$N=30$} \\
\hline & & & & & & & & & $\Delta \tau / \sigma_{0}^{\prime}$ & $\Delta \tau_{f}$ & $\tau_{f s}$ \\
\hline \multirow{6}{*}{ Shell } & \multirow{6}{*}{2.33} & \multirow{4}{*}{1.5} & 1000 & 1250 & 250 & 196 & 1095 & 0.18 & 0.463 & 454 & 649 \\
\hline & & & 2000 & 2500 & 500 & 392 & 2189 & 0.18 & 0.363 & 711 & 1103 \\
\hline & & & 3000 & 3750 & 750 & 588 & 3284 & 0.18 & 0.319 & 937 & 1525 \\
\hline & & & 1000 & 1750 & 750 & 588 & 1284 & 0.46 & 0.337 & 462 & 1050 \\
\hline & & \multirow{2}{*}{2.5} & 2000 & 3500 & 1500 & 1176 & 2568 & 0.46 & 0.216 & 592 & 1768 \\
\hline & & & 3000 & 5250 & 2250 & 1763 & 3852 & 0.46 & 0.156 & 642 & 2405 \\
\hline
\end{tabular}

TABLE 2: Parameters of cyclic shear strength.

\begin{tabular}{lcccccc}
\hline Soil & $r\left(\mathrm{~g} / \mathrm{cm}^{3}\right)$ & $N_{f}$ & $\tau_{f s 0}(\mathrm{kPa})$ & $\operatorname{tg} \varphi_{d 0}$ & $\zeta(\mathrm{kPa})$ & $\beta$ \\
\hline Shell & 2.33 & 30 & 108.5 & 0.321 & 485.6 & 0.518 \\
\hline
\end{tabular}

TABle 3: Parameters of the $E-\mu$ model and equivalent linear model.

\begin{tabular}{lcccccccccccc}
\hline Materials & $r\left(\mathrm{~g} / \mathrm{cm}^{3}\right)$ & $c^{\prime}(\mathrm{kPa})$ & $\phi^{\prime}\left({ }^{\circ}\right)$ & $k$ & $n$ & $R_{f}$ & $G$ & $F$ & $D$ & $k_{\text {ur }}$ & $k_{1}$ & $n_{1}$ \\
\hline Core & 1.58 & 86.6 & 23.7 & 202 & 0.51 & 0.87 & 0.25 & 0.04 & 2.2 & 400 & 1100 & 0.42 \\
Shell & 2.02 & 5 & 36 & 540 & 0.46 & 0.79 & 0.32 & 0.1 & 4.7 & 1100 & 1600 & 0.45 \\
\hline
\end{tabular}

Based on the above mentioned description and formulations, the two main steps to obtain the cyclic shear strength are outlined as follows. First, the total shear strength under different confining pressures and consolidation ratios can be obtained from the cyclic triaxial undrained compress tests as shown in Table 1. Second, the parameters of cyclic shear strength can be determined by linear approximation as shown in Table 2.

In some occasions concerning practical rock-fill dam design, it would be convenient for the engineers to adopt directly the static undrained shear strength into the seismic design and stability analysis, if the difference between the cyclic shear strength and its static counterpart of rock-fill materials could be negligible. However, for some particular rock-fill dams, such as rock-fill dam with clay core, sand gravel dam, and rock-fill dam built on the saturated clay or sandy deposits, the impact of cyclic shear strength on the critical acceleration and accumulation of sliding displacement would be so significant that it must be carefully considered as the liquefaction does not occur. For this purpose, available data of dynamic triaxial tests on cyclic shear strength of rock-fill materials were analyzed and a correlation between cyclic shear strength and number of cycles was obtained and listed in Tables 3 and 4 .

\section{Time History Vertical Acceleration}

In the existing Newmark-type sliding displacement analysis, the vertical earthquake is usually neglected or considered oversimply in the determination of critical acceleration and accumulation of permanent sliding displacement. Possible effects of vertical earthquake loading on the stability of Earth structures have not been discussed in detail although it had attracted great attention as early as in the 1920 s
TABle 4: Parameters of cyclic shear strength.

\begin{tabular}{lccccc}
\hline Materials & $N$ (times) & $\tau_{f s 0}(\mathrm{kPa})$ & $\tan \phi_{d 0}$ & $\zeta(\mathrm{kPa})$ & $\beta$ \\
\hline \multirow{2}{*}{ Sand layer } & 20 & 0 & 0.209 & 0 & 1.604 \\
\multirow{3}{*}{ Sand gravel } & 30 & 4.19 & 0.169 & 102.7 & 1.242 \\
& 20 & 55.05 & 0.383 & 237.4 & 0.448 \\
& 30 & 56.66 & 0.359 & 217.3 & 0.167 \\
\hline
\end{tabular}

following the devastating Kanto Earthquake in Japan. Mononobe [12] found that a combination of horizontal and vertical accelerations led to severe damage of Earth retaining structures. Ling et al. [13] and Huang et al. [14] studied the effect of vertical acceleration on the critical acceleration and sliding displacement, in which the vertical acceleration was assumed to act constantly upwards or downwards and its value was taken as a fraction of the peak horizontal acceleration. The value of $2 / 3$ was usually adopted as a reasonable ratio between vertical and horizontal acceleration based on the records of strong motion earthquake accelerations $[15,16]$.

In addition, more and more results from numerical analyses and shaking table tests revealed that the direction and phase of vertical accelerations acting on the centroid of soil slice within the flexible sliding body vary from time to time and are different for different slices during the seismic excitation, as shown in Figure 1. Consequently, it is necessary to study and clarify the influence of the distribution of time history vertical acceleration on critical acceleration and sliding displacement in order to better reflect the reality.

\section{The Modified Newmark Methodogy}

In the model we developed herein, the Bishop pseudostatic limit equilibrium method is used to determine the critical acceleration time history, factor of safety, and 


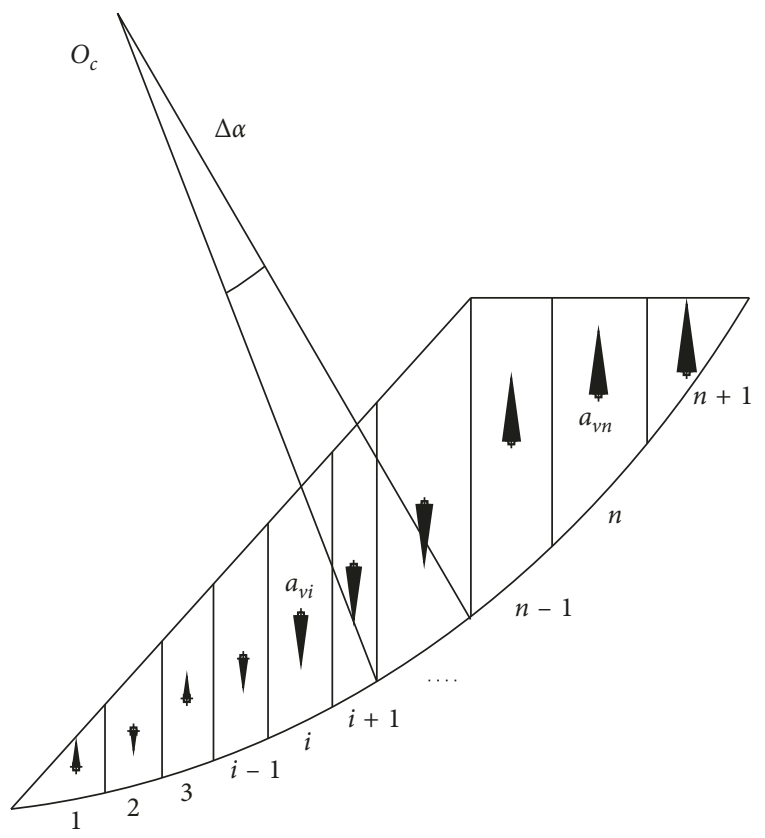

FIgURE 1: Distribution of vertical acceleration within the flexible sliding body.

location of potential slip surface [17-19]. The critical acceleration, which is still defined as the amplitude of horizontal acceleration that drives the potential sliding body into a limit equilibrium state; that is, the factor of safety equals 1.0. Noticeably, in the proposed approach, the effects of cyclic shear strength and time history vertical acceleration on the determination of the critical acceleration are considered strictly, with the detailed process shown as follows.

As shown in Figure 2, the formulation of the pseudostatic limited equilibrium method by Bishop can be rewritten by taking into consideration the cyclic shear strength $\left(\tau_{f s}\right)$ and time history vertical acceleration $\left(a_{v i}\right)$ as

$$
\begin{aligned}
F_{s}= & \frac{\sum_{i=1}^{n-m} \frac{1.0}{m_{\alpha_{i}}}\left(\left(\left(W_{i}+G_{i}\right)-u_{i} l_{i} \cos \alpha_{i}\right) \tan \phi_{i}^{\prime}+c^{\prime}{ }_{i} l_{i} \cos \alpha_{i}\right)}{\sum_{i=1}^{n}\left(\left(W_{i}+G_{i}\right) \sin \alpha_{i}+Q_{i}\left(R_{d}^{i} / R\right)\right)} \\
& +\frac{\sum_{j=1}^{m-p} \tau_{f s}^{j} l_{j}}{\sum_{i=1}^{n}\left(\left(W_{i}+G_{i}\right) \sin \alpha_{i}+Q_{i}\left(R_{d}^{i} / R\right)\right)} \\
& +\frac{\sum_{k=1}^{p} c_{r}^{k} l_{k}}{\sum_{i=1}^{n}\left(\left(W_{i}+G_{i}\right) \sin \alpha_{i}+Q_{i}\left(R_{d}^{i} / R\right)\right)}
\end{aligned}
$$

$$
m_{\alpha_{i}}=\cos \alpha_{i}+\frac{\tan \phi_{i}^{\prime}}{F_{s}} \times \sin \alpha_{i}
$$

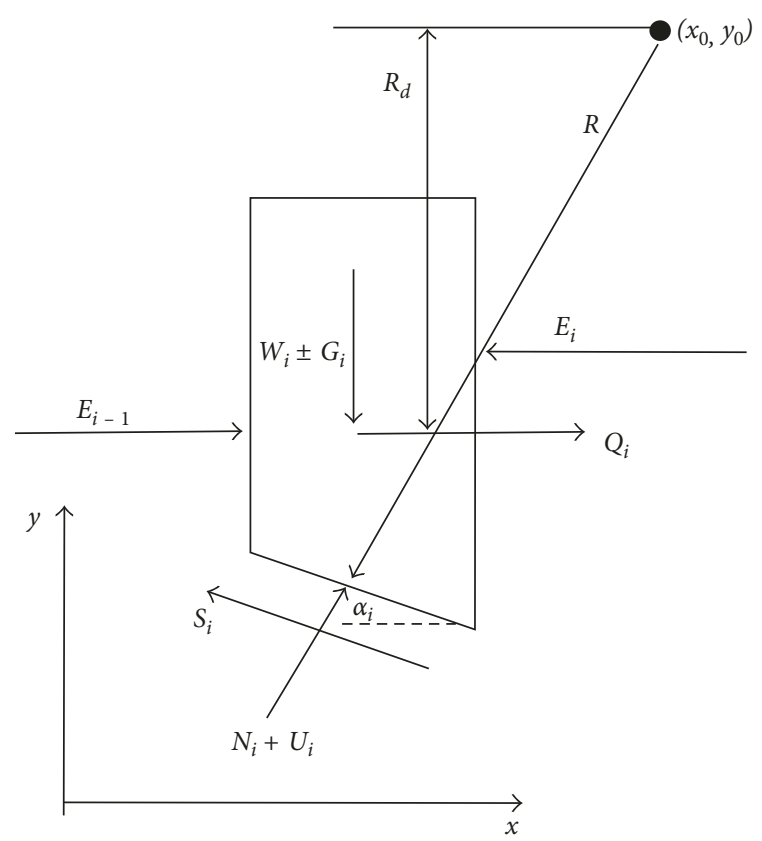

Figure 2: Diagram of forces acting on a soil slice.

$$
\begin{aligned}
& Q_{i}=k_{h, \max } c_{z} a_{h i} W_{i}, \\
& G_{i}=\frac{ \pm W_{i} a_{v i}(t)}{g},
\end{aligned}
$$

where $c^{\prime}{ }_{i}$ and $\varphi_{i}^{\prime}$ are the static effective cohesion and friction angle, respectively; $W_{i}$ is the soil weight; $u$ is the hydrostatic pore pressure; $Q_{i}$ is the horizontal inertial force obtained by (11); $G_{i}$ is the vertical inertial force caused by the time history vertical acceleration, with a positive sign indicating downward direction and vice versa; $\alpha_{i}$ represents the inclination of slice as shown in Figure $1 ; c_{z}$ is the reduction factor of horizontal inertial force, 0.25 is used in the present study; $a_{h i}$ is the distribution coefficient of horizontal inertial force along the dam height; $k_{h, \max }$ is the amplitude of the horizontal acceleration coefficient; $g$ is the acceleration of gravity; $a_{v i}$ is the time history vertical acceleration at the slice centroid obtained from dynamic response analysis; $R_{d}^{i}$ and $R$ are the vertical distances of the centroid from the center of the slip circle and the radius of slip circle, respectively; $n, m$, and $p$ are the total number of soil slices, number of slices considering the effect of cyclic shear strength, and number of slices where liquefaction occur, respectively; $\tau_{f s}^{i}$ is the mobilized cyclic shear strength; and $c_{r}$ is the residual strength of soil.

Let the factor of safety $\left(F_{S}\right)$ be 1.0, (9) can be rearranged in terms of the peak value of horizontal acceleration coefficient $\left(k_{h, \max }\right)$, as 


$$
\begin{aligned}
k_{h, \text { max }}(t)= & \frac{\sum_{i=1}^{n-m}\left[\left\{c^{\prime}{ }_{i} l_{i} \cos \alpha_{i}+\left(W_{i} \pm G_{i}-u_{i} l_{i} \cos \alpha_{i}\right) \tan \phi_{i}^{\prime}\right\} \sec \alpha_{i} / 1+\tan \alpha_{i} \tan \phi_{i}^{\prime}\right]}{\sum_{i=1}^{n} W_{i} a_{i} c_{z} R_{d i}}+\frac{\sum_{j=1}^{m-p} \tau_{f s}^{j} l_{j}}{\sum_{i=1}^{n} W_{i} a_{i} c_{z} R_{d i}} \\
& +\frac{\sum_{k=1}^{p} c_{r} l_{k}}{\sum_{i=1}^{n} W_{i} a_{i} c_{z} R_{d i}}-\frac{\sum_{i=1}^{n}\left(W_{i} \pm G_{i}\right) \sin \alpha_{i}}{\sum_{i=1}^{n} W_{i} a_{i} c_{z} R_{d i}} .
\end{aligned}
$$

Then, the coefficient of horizontal critical acceleration $\left(k_{h, y}\right)$ can be determined by the ratio of the summation of horizontal inertial force to the total weight of sliding body, as

$$
k_{h, y}(t)=\frac{\sum_{i=1}^{n} k_{h, \max }(t) c_{z} a_{h i} W}{\sum_{i=1}^{n} W_{i}} .
$$

Compared to the traditional method, it can be seen that (13) and (14) are both closed-form solutions and can be used to directly determine the coefficient of horizontal critical acceleration $\left(k_{h, y}\right)$ without any iterative process.

For the convenience of applications, the circular failure mechanism is used in this paper and several necessary transformations are performed. Considering the failure mechanism of circular slip surface, the components of driving angular acceleration $\left(\theta_{\text {ave }}\right)$ and the critical angular acceleration $\left(\theta_{y}\right)$ can be derived and expressed as

$$
\begin{aligned}
\theta_{\text {ave }}(t) & =k_{h, \text { ave }}(t) \frac{\left(y_{g}-y_{c}\right)}{R_{g}^{2}}, \\
k_{h, \text { ave }}(t) & =\frac{\sum_{i=1}^{r} m_{i} a_{h, i}(t)}{\sum_{i=1}^{r} W_{i}}, \\
\theta_{y}(t) & =\frac{\sum_{i=1}^{n} k_{h, \text { max }}(t) g c_{z} a_{h i} W_{i}}{\sum_{i=1}^{n} W_{i}} \frac{\left(y_{g}-y_{c}\right)}{R_{g}^{2}},
\end{aligned}
$$

where $R_{q}$ is the distance between the centroid of sliding body and the center of the slip surface, respectively; $y_{g}$ and $y_{c}$ are the vertical coordinate of the slip surface centroid and the center of the slip surface, respectively; $m_{i}$ is the lump mass at node $i ; a_{h, i}$ is the horizontal acceleration of node $i$ determined by dynamic response analysis; and $r$ is the number of nodes included in the slip surface.

Then the accumulation of angular sliding displacement $(\theta)$ can be obtained by the double integral of (18).

$$
\begin{gathered}
\ddot{\theta}(t)=\left[\theta_{\mathrm{ave}}(t)-\theta_{y}(t)\right] g, \\
\theta=\iint \ddot{\theta} d t, \\
S=\theta \cdot R,
\end{gathered}
$$

where $\ddot{\theta}(t)$ is the time history angular sliding acceleration.
Based on the abovementioned description and formulations, the step-by-step numerical procedure for the modified Newmark sliding displacement approach is outlined as follows:

(1) Determine the location of critical circular slip surface by (9), coupling with available optimized method

(2) Conduct the dynamic response analysis and get time history vertical inertial force acting at the centroid of each soil slice by (12)

(3) Determine the cyclic shear strength mobilized at the bottom of soil slices according to (6 8), and get the horizontal critical acceleration of potential sliding body using (13) and (14)

(4) Transform horizontal critical acceleration and driving acceleration into angular driving and critical acceleration using (17) and (18), respectively

(5) Repeat steps (2), (3), and (4) until the end of earthquake shaking and determine the accumulation of sliding displacement using (20)

\section{Verification and Application}

5.1. Example 1. A virtual core rock-fill dam with a height of $100 \mathrm{~m}$ is investigated. The cyclic shear strength for different number of cycles and the static shear strength are shown in Table 3. The input acceleration time history in the horizontal direction and vertical direction is presented in Figure 3. The amplitude of the acceleration is $0.283 \mathrm{~g}$ in the upstream-to-downstream direction, and $0.19 \mathrm{~g}$ in the vertical direction. The $E-\mu$ model and the equivalent linear analyses are performed to estimate the initial stress state and dynamic response of the dam [20]. The parameters used in static and dynamic analyses are listed in Table 5. As shown in Figure 4, the pseudostatic factor of safety and the location of the potential circular slip surface in the upstream dam slope are obtained by the Bishop limited equilibrium method. The Newmark sliding displacement analyses are performed, respectively, by the presented method and the traditional method developed by Makdisi and Seed [5]. Since in the presented method, the two factors, that is, cyclic shear strength and time history vertical acceleration, are considered simultaneously and their effects are coupled. In order to clarify the effect of each factor, a contrast analysis is performed, where only the effect of cyclic shear strength is considered and that of the time history vertical acceleration is ignored. 


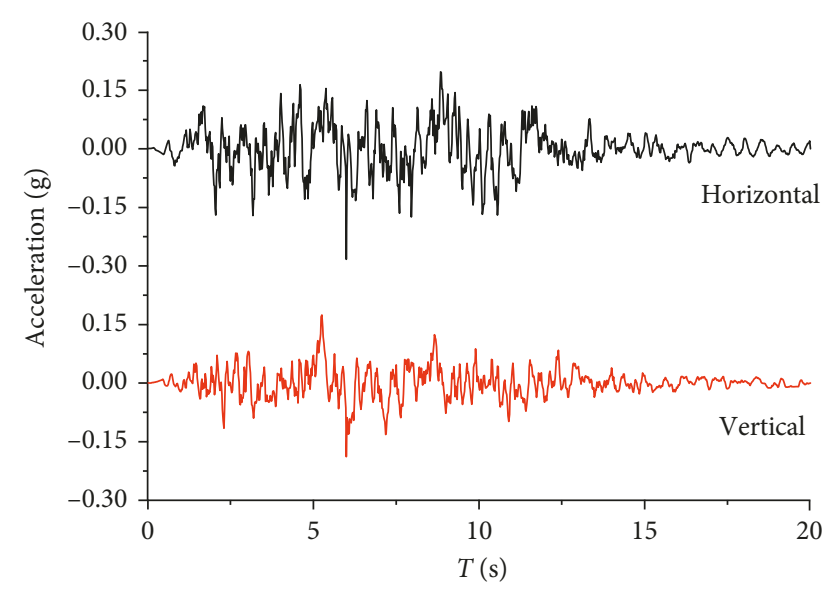

Figure 3: Accelerogram of input motion.

TABle 5: Parameters of static and cyclic shear strength.

\begin{tabular}{lccccccc}
\hline Materials & $\begin{array}{c}c^{\prime} \\
(\mathrm{kPa})\end{array}$ & $\begin{array}{c}\phi^{\prime} \\
\left.{ }^{\circ}\right)\end{array}$ & $\begin{array}{c}N \\
(\mathrm{times})\end{array}$ & $\begin{array}{c}\tau_{f s 0} \\
(\mathrm{kPa})\end{array}$ & $\tan \phi_{d 0}$ & $\begin{array}{c}\zeta \\
(\mathrm{kPa})\end{array}$ & $\beta$ \\
\hline \multirow{2}{*}{ Shell material } & \multirow{2}{*}{5} & \multirow{2}{*}{36} & 12 & 0 & 0.253 & 115.6 & 1.621 \\
& & & 20 & 8.05 & 0.193 & 107.8 & 1.25 \\
Core material & \multirow{2}{*}{86.6} & 23.7 & 12 & 83.67 & 0.333 & 92.9 & 0.417 \\
& & & 20 & 83.01 & 0.320 & 91.6 & 0.41 \\
\hline
\end{tabular}

The coefficients of horizontal critical acceleration and accumulation of sliding displacement obtained by the three different analyses are listed in Table 6. It is shown that the critical acceleration obtained by the modified method is remarkably lower than that obtained from the traditional method. The maximum difference could reach $70 \%$, as the cyclic shear strength and time history vertical acceleration are taken into consideration simultaneously. Consequently, the difference in the accumulation of sliding displacement is also considerable. The amplitude of accumulation of sliding displacement obtained from the modified method considering the effects of cyclic shear strength and time history vertical acceleration is nearly three times of that obtained from the traditional method. In addition, from Table 6 , it is clear that the accumulation of sliding displacement obtained from the contrast analysis is nearly two times of that from the traditional method, but the difference of critical acceleration and factor of safety determined by the two methods is minor. Thus, it is implied that the prediction of sliding displacement based on cyclic shear strength is important to evaluate the performance of rock-fill dams under strong earthquakes, even if the factor of safety determined based on both static shear strength and cyclic shear strength satisfies the requirements of seismic design.

Figure 5 provides the time history horizontal critical acceleration obtained from the three analyses. It is clear that the critical accelerations determined by the Makdisi and Seed method and the contrast analysis remain unchanged during the earthquake shaking. On the contrary, fluctuation of critical acceleration time history obtained from the modified method can be observed and it is correlated with the input vertical acceleration time history. Furthermore, it is noted that the minimum critical acceleration obtained from the modified method is nearly $1 / 3$ of that from the Makdisi and Seed method.

As shown in Figure 6, the modified Newmark sliding displacement method gives the highest sliding displacement during the earthquake shaking. It can be observed that the accumulation of sliding displacement obtained by the traditional method stops growing at 10 seconds, whereas the growing trend stops at 15 seconds for the modified Newmark sliding displacement analysis. Compared with the traditional method, the times of sliding episodes and increment of sliding displacement in one sliding episode presented in the modified Newmark sliding displacement analyses are bigger because of the lower time history critical acceleration. It implies that the modified method predicts a sliding episode, whereas the traditional analysis predicts dam slope stability, as the value of driving acceleration lies between the two critical accelerations. In addition, from the engineering point of view, the accumulation of sliding displacement, which is regarded as a key index for the safety evaluation of high core rock-fill dams subjected to design earthquake, obtained by the traditional method tends to be unsafe as the effects of cyclic strength and time history vertical acceleration on the critical acceleration are ignored.

5.2. Example 2. The following is a practical core rock-fill dam of $150 \mathrm{~m}$ in height which will be built on deep overburden foundation. It is noted that the deep overburden layer of the dam site is thicker than $500 \mathrm{~m}$ and has a weak sand inclusion layer with a thickness of $20 \mathrm{~m}$. The maximum cross section and finite element mesh are provided in Figure 7. The dam is mainly composed of core, shell, sand layer, and sandy gravel. The simulation of filling and water storage is conducted by static analysis with the $E-\mu$ model, and the equivalent linear analyses are performed to obtain the response of acceleration and dynamic shear stress. As shown in Figure 7, the pseudostatic factor of safety and the locations of the potential circular slip surfaces in the upstream and downstream dam slopes are obtained by the Bishop limited equilibrium method. The parameters of static analysis, dynamic analysis, and cyclic shear strength of sand layer are presented in Tables 4 and 7 and obtained from the laboratory triaxial compression test. The design ground motions were selected based on in situ investigations. The acceleration time histories in the horizontal direction and vertical direction are plotted in Figures 8 and 9, respectively, with amplitudes of $0.535 \mathrm{~g}$ and $0.36 \mathrm{~g}$, respectively. In the time marching process of equivalent linear analyses, the duration of the earthquake excitation (40 seconds) is divided into 15 periods.

Based on the results obtained from the dynamic triaxial tests and dynamic response analysis, the distribution of ratio of cyclic shear strength to static shear strength $\left(\tau_{f s} /\left(c^{\prime}+\sigma_{f 0}^{\prime} \tan \phi^{\prime}\right)\right)$ for the sand layer and sand gravel is provided in Figure 10. It is shown that the cyclic shear strength of most of the soil elements located in the sand 


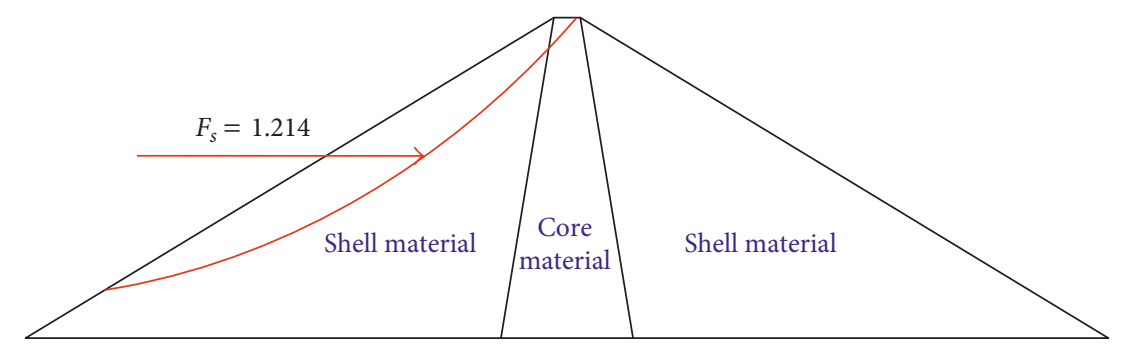

FIgURE 4: Potential circular slip surface and factor of safety of dam under design earthquake.

TABLE 6: Horizontal critical acceleration, sliding displacement, and factor of safety.

\begin{tabular}{lccc}
\hline Items & $\begin{array}{c}\text { Traditional } \\
\text { method }^{1}\end{array}$ & $\begin{array}{c}\text { Contrast } \\
\text { analysis }^{2}\end{array}$ & $\begin{array}{c}\text { Modified } \\
\text { method }^{3}\end{array}$ \\
\hline $\begin{array}{l}k_{h, y}(\mathrm{~g}) \\
s(\mathrm{~cm})\end{array}$ & 0.152 & 0.134 & $0.045^{\#}$ \\
Factor of safety & 24.2 & 42.1 & 68.4 \\
\hline
\end{tabular}

${ }^{1}$ The traditional method is the approach in which the static shear strength is used. ${ }^{2}$ The contrast analysis is the approach in which only the cyclic shear strength is considered in the modified method. ${ }^{3}$ The modified method is the approach in which the cyclic shear strength and time history vertical acceleration are considered simultaneously. "The minimum critical acceleration during the earthquake shaking.

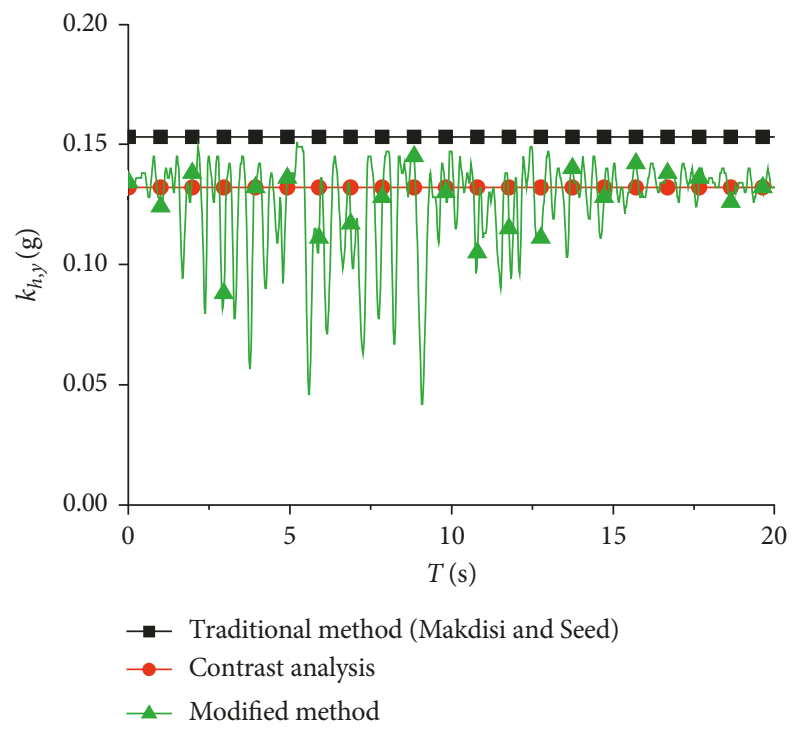

FIgURE 5: Time history horizontal critical acceleration.

layer and sand gravel layer is lower than the static shear strength, but it is noted that the liquefaction does not occur. The difference between the static shear strength and cyclic shear strength is noticeable, and the maximum difference at the toe of the upstream dam is around 50\%. Thus, considering the great part of failure surface located in the sand layer and sand gravel layer as shown in Figure 7, the impact of cyclic shear strength on the critical acceleration and sliding displacement should be considered.

The modified Newmark sliding displacement method is used to determine the time history driving acceleration,

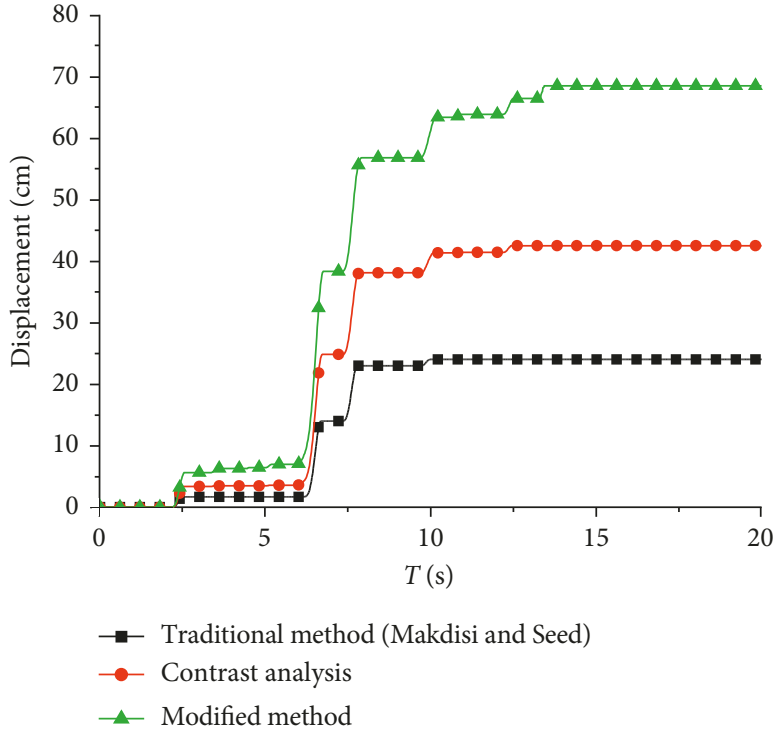

FIgURE 6: Time history sliding displacement.

critical acceleration, and accumulation of sliding displacement, with the results shown in Figures 11-13. Fluctuation of the critical acceleration time history can be observed because of that considering the effect of time history vertical acceleration which is obtained from equivalent linear dynamic response analysis. There are, respectively, two and four obvious intersections between the angular critical acceleration and angular driving acceleration as shown in Figures 11 and 12. It can be observed that the minimum of time history critical acceleration of slip surface in downstream dam slope which corresponds to factor of safety of 0.93 which is smaller than that of slip surface in upstream dam slope which corresponds to factor of safety of 0.88 . Meanwhile, the time history driving acceleration of slip surface in the upstream dam slope is bigger than that of slip surface in downstream dam slope during the earthquake shaking. As shown in Figure 13, the magnitudes of sliding displacements of slip surface in upstream dam slope and downstream dam slope are $34.0 \mathrm{~cm}$ and $5.5 \mathrm{~cm}$, respectively. It is noted that the increment of sliding displacement of slip surface in upstream dam slope occurred in the first sliding episode is about $32 \mathrm{~cm}$ and makes an offer of $95 \%$ of total accumulation of sliding displacement. This can be contributed to the remarkable difference of driving acceleration and critical acceleration for the reason that the effects of cyclic shear strength, time 


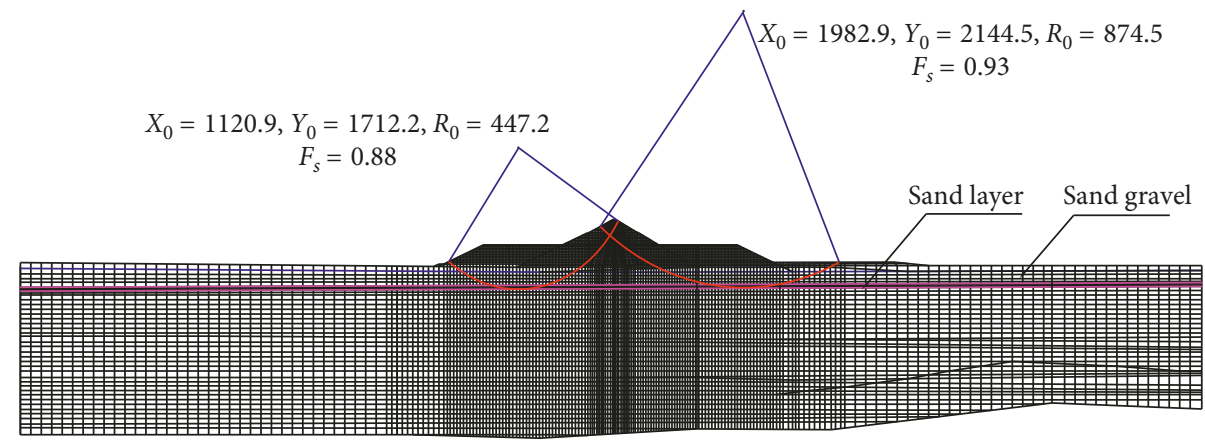

Figure 7: Cross section of the dam and potential slip surfaces.

Table 7: Parameters of the $E-\mu$ model and equivalent linear model.

\begin{tabular}{lcccccccccccc}
\hline Materials & $r\left(\mathrm{~g} / \mathrm{cm}^{3}\right)$ & $c^{\prime}(\mathrm{kPa})$ & $\phi^{\prime}\left(^{\circ}\right)$ & $k$ & $n$ & $R_{f}$ & $G$ & $F$ & $D$ & $k_{\mathrm{ur}}$ & $k_{1}$ & $n_{1}$ \\
\hline Core & 2.2 & 35 & 33 & 447 & 0.4 & 0.75 & 0.39 & 0.05 & 1.9 & 900 & 1600 & 0.53 \\
Shell & 2.3 & 0 & 45 & 1050 & 0.37 & 0.71 & 0.3 & 0.09 & 5.8 & 2100 & 4600 & 0.42 \\
Sand layer & 1.55 & 40 & 32 & 280 & 0.43 & 0.81 & 0.42 & 0.13 & 2 & 600 & 600 & 0.5 \\
Sand gravel & 2.27 & 0 & 47 & 836 & 0.35 & 0.79 & 0.32 & 0.1 & 4.8 & 1700 & 4544 & 0.35 \\
\hline
\end{tabular}

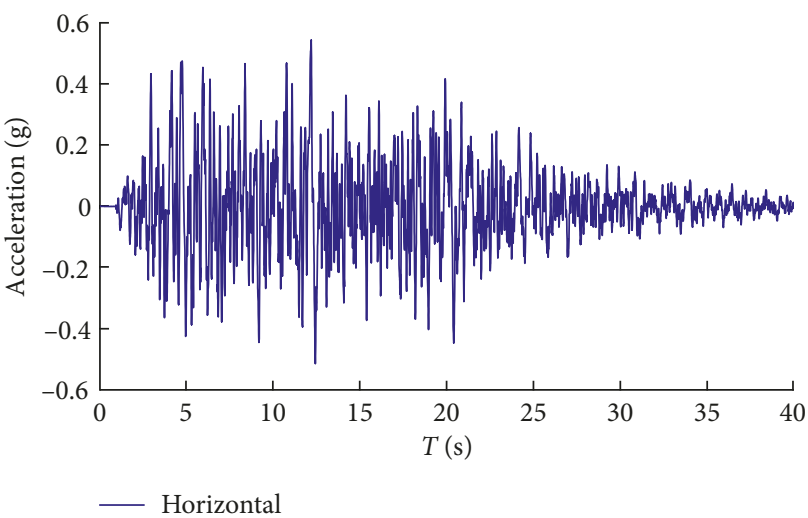

FigURe 8: Accelerogram of horizontal input motion.

history vertical acceleration, and location of flexible sliding body. Consequently, it is justified that the effects of cyclic shear strength and time history vertical acceleration on the critical acceleration and sliding displacement for flexible sliding body are considerable, especially to the foundation of the rock-fill dams with a weak sand layer.

\section{Conclusions}

A modified Newmark-type methodology for sliding deformation analysis of rock-fill dams subjected to strong earthquake is developed. The effects of cyclic shear strength and time history vertical acceleration on the sliding displacement are considered in detail. Based on detailed comparisons between the proposed method and traditional method (Makdisi and Seed's method), it can be seen that the effect of earthquake-induced reduction of shear strength (cyclic shear strength) and time history vertical acceleration

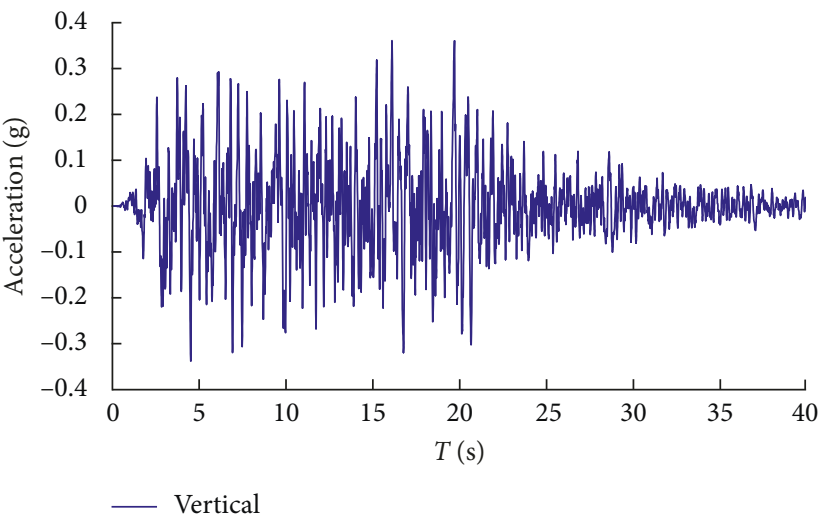

Figure 9: Accelerogram of vertical input motion.

on the critical acceleration and sliding displacement is remarkable. On the other hand, the necessity and feasibility of the proposed method is also verified by the application to the analysis of a real core rock-fill dam which will be built on deep overburden foundation with weak sand layer. It is shown that the cyclic shear strength is generally lower than the static shear strength in the weak sand layer as the liquefaction does not occur during a strong earthquake shaking and the time history vertical acceleration can play an important role in the dam stability evaluation based on the Newmark-type sliding displacement analysis.

As it is known that reliable and convenient prediction of earthquake-induced sliding displacement is crucial for the seismic design of rock-fill dams, it is shown from the numerical examples that there is noticeable difference between the displacement obtained by taking into account the effect of cyclic shear strength and time history vertical acceleration and the displacement obtained by the traditional Newmark 


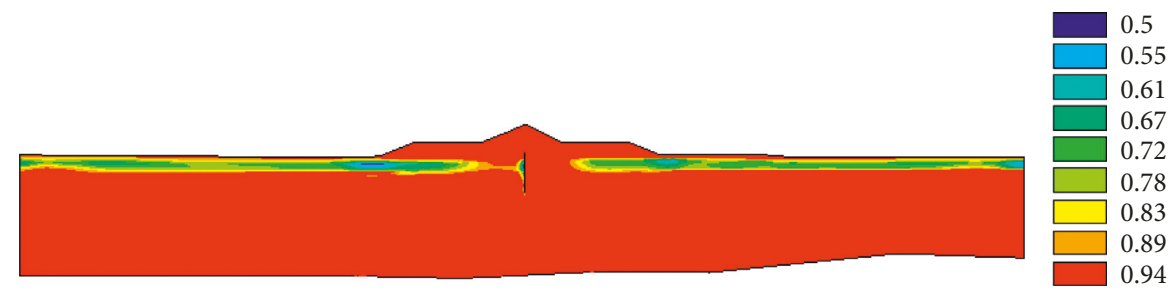

Figure 10: The distribution of ratio of cyclic shear strength to static shear strength.

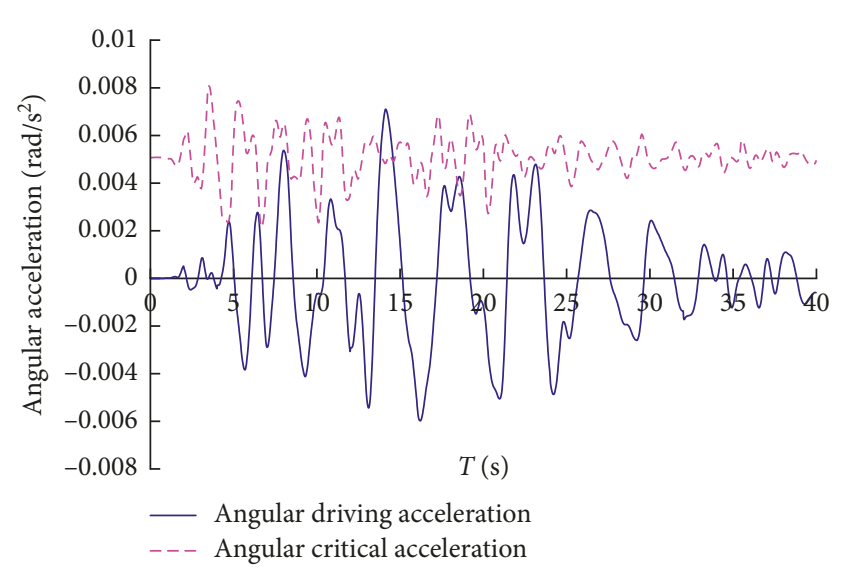

FIGURE 11: Time history angular driving acceleration and critical acceleration of slip surface in upstream dam slope.

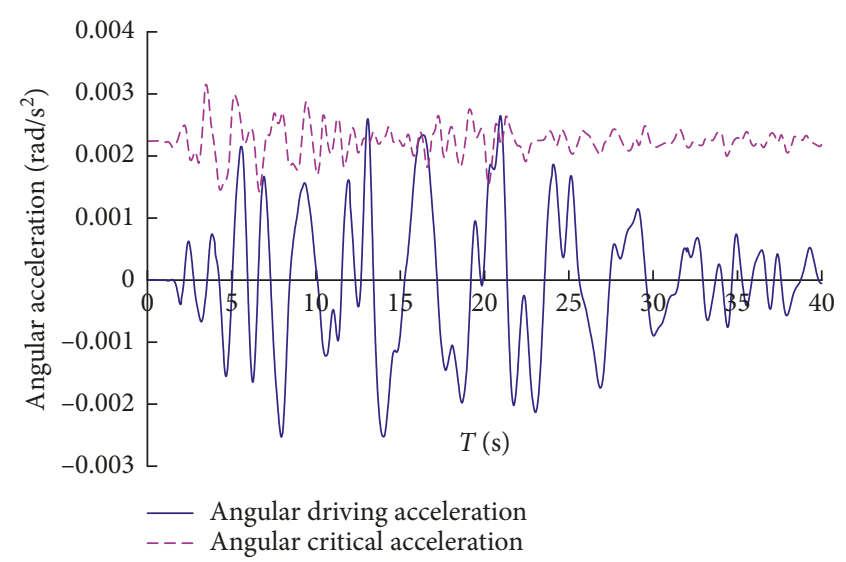

Figure 12: Time history angular driving acceleration and critical acceleration of slip surface in downstream dam slope.

method, and this would exert important consequences in the seismic stability analysis of a rock-fill dam:

(1) When the liquefaction-induced damage does not occur, as the cyclic shear strength is significantly lower than the static shear strength for rock-fill materials and weak sand layer, the analysis presented herein predicts a general failure of dam slope, whereas the traditional Newmark-type analysis would predict dam slope stability.

(2) In the high rock-fill dams, the time history of vertical acceleration in the flexible sliding body can play an

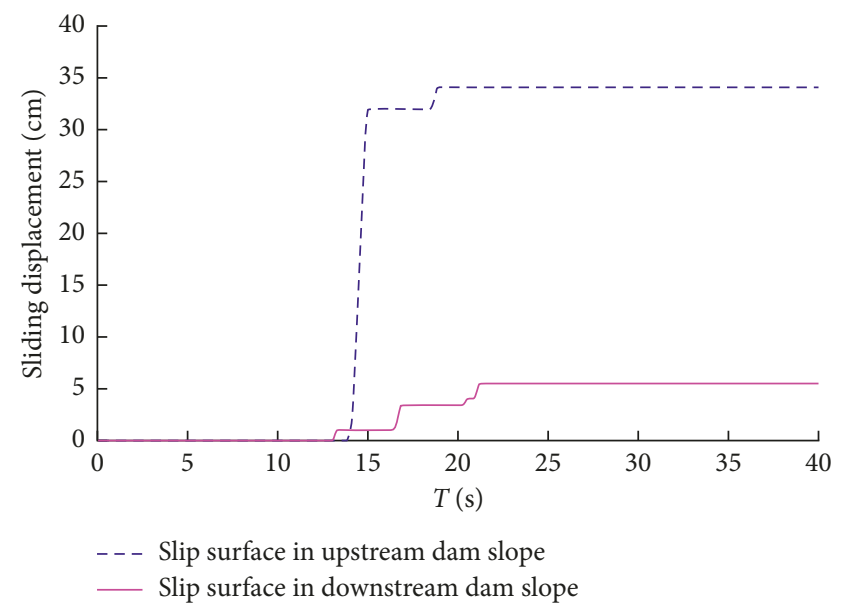

FIgURE 13: Time history sliding displacements of slip surfaces in upstream and downstream dam slopes.

important role in the Newmark-type sliding displacement analysis, and the traditional method could provide unsafe prediction of seismic stability of rockfill dams.

In a word, the proposed methodology for sliding displacement analysis of rock-fill dams as the liquefaction would not occur leads to more realistic evaluation of the permanent displacement, and it provides a promising alternative to routine seismic design and evaluation of the mitigation measures for high rock-fill dam with a high level of confidence.

\section{Conflicts of Interest}

The authors declare that they have no conflicts of interest.

\section{Acknowledgments}

The financial support by the National Key Research and Development Program of China through Grant no. 2017YFCC0404904, the National Nature Science Foundation of China (51579033), the National Key Basic Research Program of China (no. 2013CB036404), and the Public Service Sector R\&D Project of Ministry of Water Resource of China (no. 201501035) and experimental data and technological supports from IWHR Laboratory are gratefully acknowledged. 


\section{References}

[1] A. A. Farghaly, "Evaluation of seismic performance of buildings constructed on hillside slope of Doronka villageEgypt," ISRN Civil Engineering, vol. 2014, Article ID 940923, 13 pages, 2014

[2] J. Song, Y. Gao, A. Rodriguez-Marek, and T. Feng, "Empirical predictive relationships for rigid sliding displacement based on directionally-dependent ground motion parameters," Engineering Geology, vol. 222, pp. 124-139, 2017.

[3] Y. G. Zhou, J. Chen, Y. She, and A. M. Kaynia, "Earthquake response and sliding displacement of submarine sensitive clay slopes," Engineering Geology, vol. 227, pp. 69-83, 2017.

[4] N. M. Newmark, "Effects of earthquakes on dams and embankments," Geotechnique, vol. 15, no. 2, pp. 139-160, 1965.

[5] F. I. Makdisi and H. B. Seed, "Simplified procedure for estimation dam and embankment earthquake induced deformations," Journal of the Geotechnical Engineering Division (ASCE), vol. 104, no. 7, pp. 849-868, 1978.

[6] H. B. Seed and R. V. Whitman, "Design of earth retaining structures for dynamic loads," in Proceedings of the Lateral Stress Ground and Design of Earth Retaining Structures (ASCE), pp. 103-147, Ithaca, NY, USA, June 1970.

[7] W. Wenshao, The Characteristic of Cyclic Strength and Liquefaction of Soil, China Electric Power Press, Beijing, China, 1996.

[8] Z. Li and M. Luan, "Evaluation of aseismic stability of soil embankments considering cyclic degradation of soil strength," Rock and Mechanics, vol. 25, no. 2, pp. 409-417, 2004.

[9] S. Y. Wang and X. B. Lu, "Post-cyclic strength degradation of undisturbed and remolded marine silty clay," in Proceedings of the 18th International Offshore and Polar Engineering Conference (ISOPE 2008), Vancouver, Canada, July 2008.

[10] A. F. L. Hyde and S. J. Ward, "The effect of cyclic loading on the undrained shear strength of silty clay," Marine Geotechnology, vol. 6, no. 3, pp. 299-314, 1986.

[11] C. Xu, J. Jia, Y. Sun, X. Du, and Y. Gao, "Cyclic strength of saturated sand under bi-directional cyclic loading," Engineering Geology, vol. 227, pp. 23-31, 2017.

[12] N. Mononobe, "Effects of vertical acceleration and theory of vibration," Proceedings of the Japan Society of Civil Engineers, vol. 10, no. 5, pp. 1063-1094, 1924.

[13] H. I. Ling, D. Leshchinsky, and M. Yoshiyuki, "Soil slopes under combined horizontal and vertical seismic accelerations," Earthquake Engineering and Structural Dynamics, vol. 26, no. 12, pp. 1231-1241, 1997.

[14] J. L. Huang, W. Z. Wang, and H. J. Xue, "Dynamic analysis of seismic stability of slopes," Earthquake Engineering and Engineering Vibration, vol. 17, no. 4, pp. 113-122, 1997.

[15] N. M. Newmark and W. J. Hall, Earthquake Spectra and Design, Earthquake Engineering Research Institute, Berkeley, CA, USA, 1982.

[16] J. Ingles, J. Darrozes, and J.-C. Soula, "Effects of the vertical component of ground shaking on earthquake-induced landslide displacements using generalized Newmark analysis," Engineering Geology, vol. 86, no. 2-3, pp. 134-147, 2006.

[17] K. Jinman and M. Nicholas Sitar, "Direct estimation of yield acceleration in slope stability analyses," Journal of Geotechnical and Geoenvironmental Engineering, vol. 130, no. 1, pp. 111-115, 2004.

[18] L. Li, S.-C. Chi, and G. Lin, "The complex method based on ant colony algorithm and its application to the slope stability analysis," Chinese Journal of Geotechnical Engineering, vol. 26, no. 5, pp. 691-696, 2004.

[19] H. Li, H. Zhong, Z. Yan, and X. Zhang, "Particle swarm optimization algorithm coupled with finite element limit equilibrium method for geotechnical practices," Mathematical Problems in Engineering, vol. 2012, Article ID 498690, 14 pages, 2012

[20] H. Li, S. Chi, G. Lin, and H. Zhong, "A modified approach for determination of nonlinear properties in seismic response analyses for $200 \mathrm{~m}$ high core rock-fill dams," Canadian Geotechnical Journal, vol. 45, no. 8, pp. 1064-1072, 2008. 


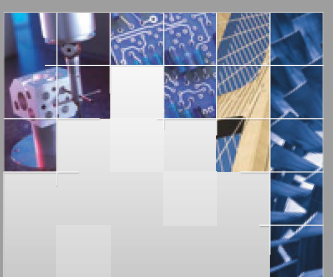

\section{Enfincering}
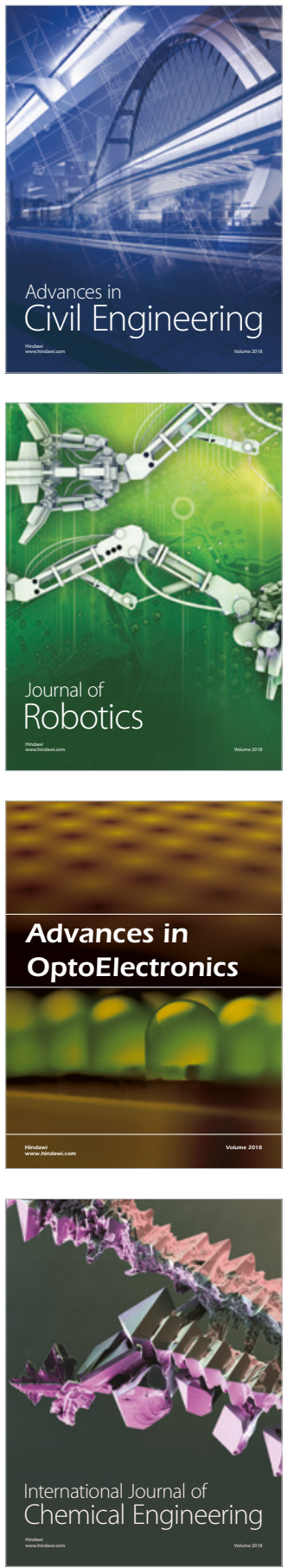

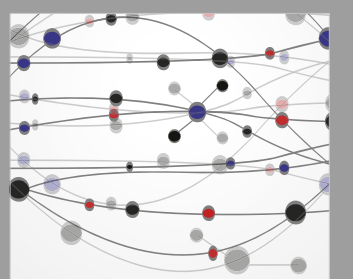

\section{Rotating \\ Machinery}

The Scientific World Journal

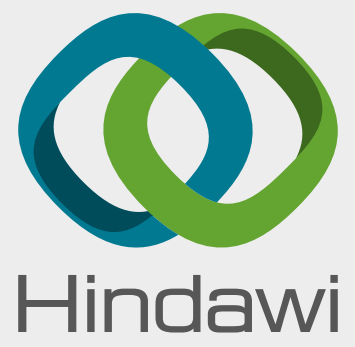

Submit your manuscripts at

www.hindawi.com
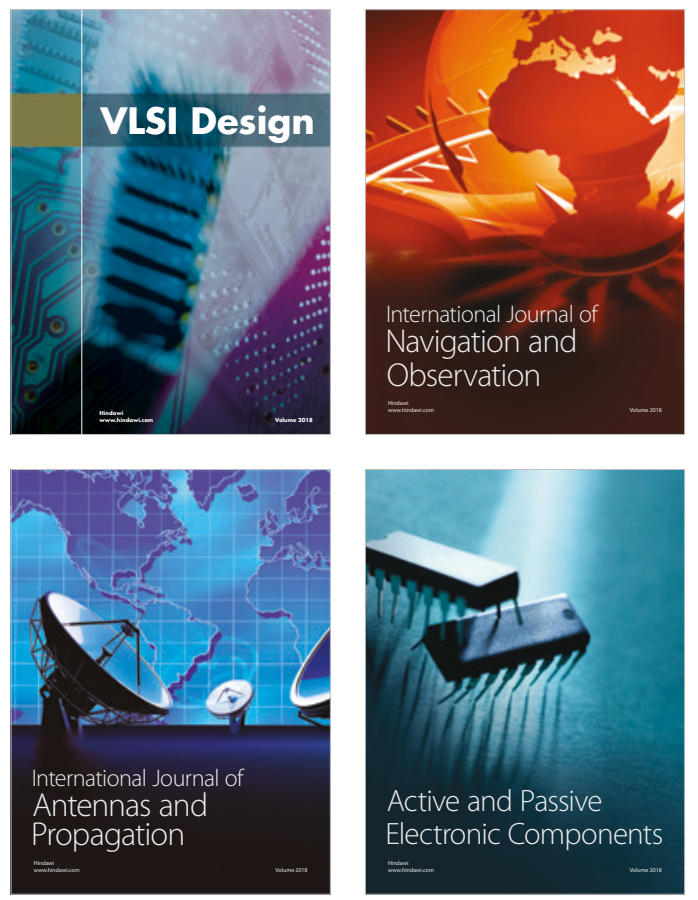
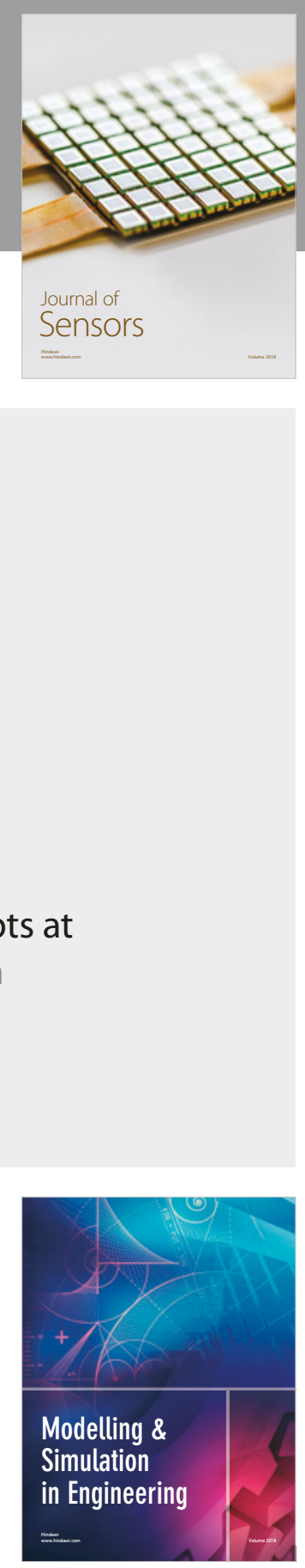

\section{Advances \\ Multimedia}
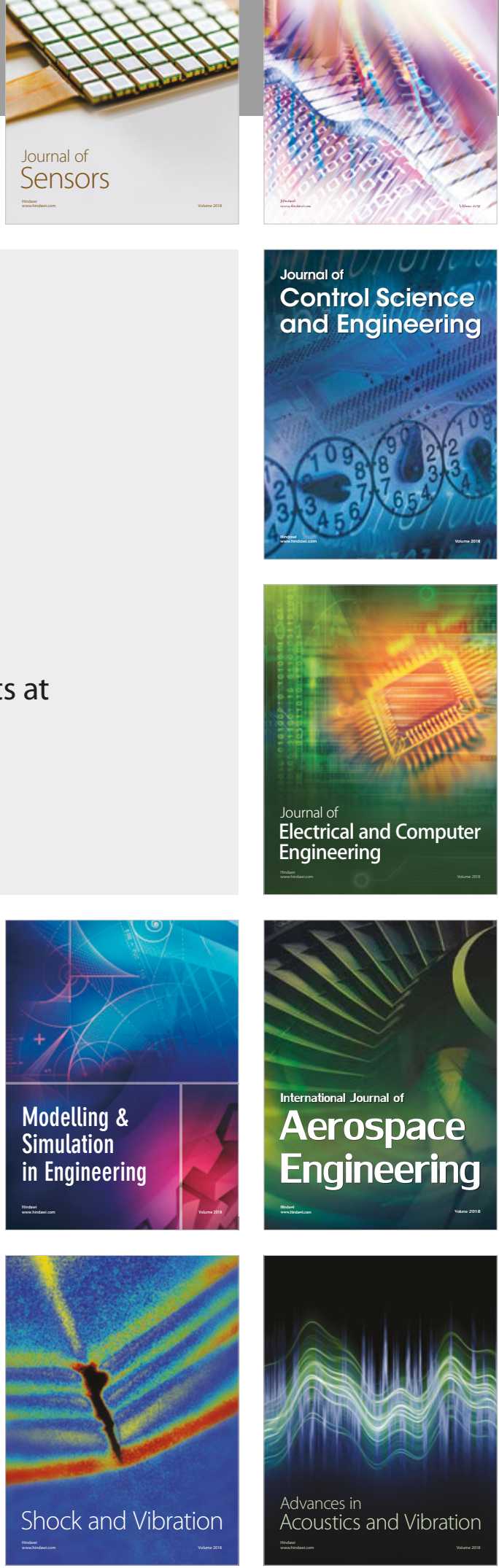